\title{
Design and Optimization of Direct Drive Motor Alloy Wheel for Manual Wheelchair
}

\author{
Sateesh Reddy Avutu, Biomedical Engineering Department, North Eastern Hill University, India \\ Sudip Paul, Biomedical Engineering Department, North Eastern Hill University, India \\ iD https://orcid.org/0000-0001-9856-539X
}

\begin{abstract}
The wheelchair is the primary rehabilitation device used to enable the movement capability of disabled people. Its usage depends on the pre- and post-hospitalization of the patient. To provide an appropriate wheelchair, the doctor will suggest the necessary changes like wheelchair type, size, seat, and add-on devices. However, the customization of a manual wheelchair is easy and cost-effective compared with the powered wheelchair due to simple structure and spare parts availability in the market. Because of the above, a novel concept is proposed. The rear wheels of the manual wheelchair are replaced with a direct drive motor alloy wheel. CATIA - V5 is utilized to design the proposed wheel, and ANSYS software is used to check its performance at different load conditions. The stress-bearing capability of different materials for various direct drive motor weights is observed through structural analysis. The natural mode frequencies are found using modal analysis, and its nature of vibrations is verified. The harmonic response analysis is used to test the nature of deformation and stress concerning natural frequencies for the applied force. The feasibility of the proposed wheel for real-time implementation along with future work is dealt with in conclusion.
\end{abstract}

\section{KEYWORDS}

Alloy, Casting, Deformation, Direct Drive Motor, Dynamic, Modal, Rehabilitation, Static, Stress, Von-Mises, Wheel

\section{INTRODUCTION}

The wheelchair is preferred to avoid mobility issues that occur due to disability, injury, and illness. According to the World Health Organization (WHO), 15\% of people of the world population suffers due to various kinds of disabilities. In India as per the Census 2011, 2.21\% of the total population has a disability Avutu et al. (2017). The design specifications and type of wheelchair must be based on the needs of the user. How-ever needs of the user depending on their disability, purpose, age, gender, and atmospheric conditions. The Rehabilitation purpose wheelchair is quite different from the sports wheelchairs and these are classified as a manual and powered wheelchair. There are several designs with specified applications are available in the global market, but its cost is quite high and beyond the user purchase capacity. The emerging technologies lead to inventing smart wheelchairs. But, unfortunately, these inventions are not reached to the village people of the low-income countries. The long term usage of the manual wheelchair causes severe shoulder injury to lead to surgery. The

DOI: 10.4018/IJSDA.20211001.oa10

This article published as an Open Access article distributed under the terms of the Creative Commons Attribution License (http://creativecommons.org/licenses/by/4.0/) which permits unrestricted use, distribution, and production in any medium, provided the author of the original work and original publication source are properly credited. 
propelling capacity of the user is depending upon the success rate of the surgery Jordan et al., (2018). Sometimes the users may not able to propel his wheelchair, in such cases, they have to depend on the caregiver to do his daily routine activities which are quite difficult it may cause an extra financial problem. In this article, an attempt has been made to bring the facilities of the powered wheelchair within the manual wheelchair to enhance the independence of the wheelchair users.

The recent developments in computer science have led to invent simulation software in the engineering field. Simulation and validation are crucial parts of any product manufacturing and initial step of 3D-CAD modal design. A good simulation work can improve the strength of the product at a low manufacturing cost and also increases the sales in the market. But, the defective error similarity between the simulation and real-time model depends on the interpreted results. It has applications in many industries like architecture, aerospace, electronics, automobiles, and household products manufacturing. It can help to study the behavior of the device without physically building. Design simulation tools help to verify the product design parameters like safety, lifespan, strength, Energy requirement, deterioration, design flaws, and to ensure optimum use. It is easier for the designer to make any changes in digital form products rather than the prototype model and helps to develop a low cost-efficient product for consumers. The product design in the digital form helps the manufacturer as a reference for future developments

Computer-Aided Three-dimensional Interactive Application (CATIA-V5) is a multi-platform Computer-Aided Design (CAD) software used in surface modelling and high-end products. Analysis Systems (ANSYS) is a mechanical software used to study the dynamic, structural, linear, and nonlinear behavior of the product based on Finite Element Analysis (FEA). In general, either structural steel or stainless steel are the materials used to make manual wheelchair rear wheels. Although the cost is low, these materials have heavyweight compared with alloy materials. It makes the total wheelchair weight bulky. The quick acceleration and faster stop can improve with a lightweight wheel. While selecting the alloy material for product design the properties like Machinability, Structural properties, Impact strength, Process cost, Alloy cost Bearing properties, and wear resistance has to consider. The Aluminum alloy remains one of the most economical materials used in the manufacturing industry. The Magnesium alloy has low density and weight.

In the remaining part of the article, related work is elaborated in section -2 . The methodology used for design and analysis is discussed in section -3 . The strength of the projected design, observations, and demerits along with the future work is presented in sections -4 and 5 respectively.

\section{RELATED WORK}

Heavyweight, complex structure and bulkiness are the major challenges with a currently powered wheelchair in the market. Chong et al., (2019) has done an experiment to replace the structure of the frame with lightweight carbon composite material. The weight-bearing capacity of a foldable wheelchair is verified through the structural analysis using Structure Mechanics Module of COMSOL Multyphysics. The results show the high safety factor confirms the safety level of the proposed design. But the authors did not discuss the material and size of the wheel used. Manual cum powered wheelchair design has proposed Avutu et al., (2017). The speed control of the proposed module may not be accurate due to the complex behavior of a gear system. The assistive powered module is discussed by Avutu et al., (2017). In this case, the rotational power is transferred through the belt system. It may not suitable for real-time implementation since the manufacturing of the desired size belt is difficult. Stretcher cum wheelchair robot is proposed by Sang et al., (2020) but, the weight and bulkiness of the modal are not addressed. The concept of a spoke wheel with a direct drive hub motor was discussed Avutu et al., (2019). The sustainability of the wheel is not conferred for outside environments such as muddy and sandy. Spoke covered try wheel mechanism for stair climbing is presented by Kim et al., (2019). This design is used only indoor and the reality of the prototype modal is not justified.

Mistarihi et al., (2020) proposed a new wheelchair design to improve the poor body postures. This modal is ergonomically validated by quality function development. A prototype modal of a 
hybrid wheelchair with an exoskeleton is designed and analyzed by Song et al., (2019). This design may help the user to protect themselves from the pressure sours. But, in real-time the users need the training to learn how to use the device as a safety concern. (Md Zahid \& Moshiur, 2019) proposed stair climbing cart with eight-wheel made with locally available motors for developing countries to reduce the human effort while carrying the goods. A wheelchair robot is described Murray et al., (2019) to provide active postural support. This is design is meant for people with trunk motor impairments. It not ergonomically designed to evaluate the effectiveness of using human subjects. The comprehensive review is made by (Flemmer \& Flemmer, 2016) to discuss the changes take place in manual wheelchair design in last 1.5 decade. Fuzzy based adaptive control for two-wheeled mobile robots has discussed (Kharola \& Patil, 2017). This kind of technique leads to develop autonomously navigated wheelchair (Yasuda, 2020). H. A. Hussein et al (2017)., proposed a fault detection of stator inter-turn short circuit in a three-phase induction motor based on artificial intelligence. It can use to control the motor speed at the desired levels. Salima et al., (2018). (Nikabadi \& Hakaki, 2018) explained about the dynamic factors of open Innovation in the Manufacturing sector.

\section{PROPOSED METHODOLOGY}

The developments in the field of engineering and technology have to be used to build the best society. In this view, a novel concept is proposed to replace the hub of the manual wheelchair with direct drive motor [figure - 1(a)]. The alloy type wheel design is preferred since it has made off with a single metallic block. Compared with spokes wheel alloy wheel has more life span, Durable, lightweight, endure the stress from all directions, sturdier, best dynamic ability, and free of human interference and errors. These wheels are perfectly fit to the tubeless tires. It improves the wheelchair stability and makes it easier for a puncture repair. FEA has used to solve real-time engineering problems involve in different physics such as electromagnetism, heat transfer, fluid flow, stress, and strain. 3D CAD model design, mesh construction, and impose load and boundary conditions are the steps of the FEA process.

The forces acting on the structure during the functional operation of an object are called load. Based on the operating conditions structural analysis can used to solve the different problems like bucking, static, vibration, frequency response, and transient dynamics. It may Linear or Nonlinear analysis. In Nonlinear analysis, Geometry changes resulting in stiffness change. Material deformation that may not return to the original form. Supports changes in load direction and constraint locations and nonlinear load curves. In Linear analysis, the structure returns to the original form with small changes in shape stiffness. No changes in loading direction or magnitude and material properties. It has used to calculate the load effects like von Mises stress and deformation on the physical structure to ensure the structural integrity of the proposed system. Von Mises stress is multi-axial stress. The normal stress calculated at an angle when shear stress considered zero is treated as principal stress. The three principal stresses can form as coordinates and the resulting von Mises stress. In general, materials like steel shows a plastic deformation and yielding before undergoing fracture. The stresses calculated at any point can be mathematically written into a scalar quantity known as von Mises stress. It can be compared with experimentally observed yield points.

The factor of safety (FOS) is defined as the ratio of maximum stress to the permissible stress. It always a numerical value greater than one. Material selection, load type, Economy, component role over the whole machine, and components lifespan are the factors that influence the value of FOS. The higher FOS value reduces the working stress on the material, which prevents the failure of the component. The mathematical formula of FOS for Ductile and Brittle material have given below.

$$
\text { FOS for Ductile material }=\frac{\text { Yield Stress }}{\text { Working Stress }}(1)
$$

Any process that affects the size, shape, area and volume of the material is called deformation. If the area can retain its original shape after the strain is called elastic deformation. If the area does not 
recover from the change in shape is called plastic deformation. When the material is folded or bent without breaking is called ductile deformation. When a material breaks under stress is called brittle deformation. The ANSYS software can provide the directional deformation and total deformation. The square root of the summation of the square of $\mathrm{x}$-direction, $\mathrm{y}$-direction, and z-direction deformation is called total deformation.

The Modal analysis has used to identify the mode shapes, natural frequencies, damping loss factors and modal constants of any structure subjected to excitation then left free. It determines all the possible unforced free vibration natural mode shapes of the concerned structure without any damping. This data help for performing forced vibration. It has to be conducted under a no-load condition. During this analysis Linear elastic material behavior, excitation of the structure is assumed and no non-linarites, damping are not included. The user has to provide the frequency range and the required number of frequency modes during the simulation. The point mas can be used to assign the mass to the required object. It doesn't add any stiffness to the object. The distributed weight on selected surfaces has to include to decrease the natural frequency value in free vibration analysis. The user has to provide the proper boundary conditions since it affects the frequencies and mode shapes of the object. The Harmonic analysis has been used to determine the steady-state sinusoidal response to all sinusoidal varying loads acting at a specified frequency. like structural analysis the user has to provide the load for individual frequency. The frequency at which the loading occurs is called excitation frequency. Any type of object may be present in this analysis. After the simulation, the results are in the form of contour images and two-dimensional graphs. At a given frequency and phase angle images give the component value like stress and displacement. All the design works have carried using CATIA-V5 software since it has user-friendly tools compared with other software. Simulation works have done using ANSYS software. Linear analysis has done on the proposed model due to the limitation of the software. The detailed proposed methodology is given below.

\subsection{Design Procedure}

The Direct-drive hub motor is designed. The diameter of the rear wheel is chosen as 508, 610 and $660 \mathrm{~mm}$ since these wheels are readily available in the market. Instead of wire spokes, hallow alloy type material with two millimeters $(2 \mathrm{~mm})$ thickness has used to establish the connection between the wheel rim and a direct-drive motor [figure-1(b)]. The Geometry for the proposed design is shown in figure -2 .

\subsection{Analysis Procedure}

The designed model is saved in Initial graphics exchange specification (IGES) and the same is used as the geometry file. The maximum speed of the direct-drive motor is depending on the average airgap flux density, electrical loading which depends on the number of turns on the coil and amount of current drawn. The changes in the above parameters can cause changes in the physical parameters like size and weight, to justify this the performance analysis is done for different motor weights like 29.41, 49.03, 68.64, and 98.06 Newton's. The static structural analysis is used to verify the load-bearing capacity, modal analysis is selected to find the natural vibrations and corresponding frequencies and finally, the deformation and von Mises stress concerning each natural frequency are found with the help of Harmonic analysis. The von Misses stresses and the corresponding deformation are calculated by selecting each material separately for 508, 610, and $660 \mathrm{~mm}$ diameter wheel with different motor weights.

\subsection{Material Selection}

At present two materials named Aluminum and Magnesium are used in the automotive industry to make bike alloy wheels. Research has been done to identify suitable material among the Four Various Aluminum and three Magnesium alloy materials. These materials have selected based on availability in the market. However, each material has its properties, cost in the open market is depending on 
Figure 1. The proposed Direct drive motor and wheel with boundary conditions

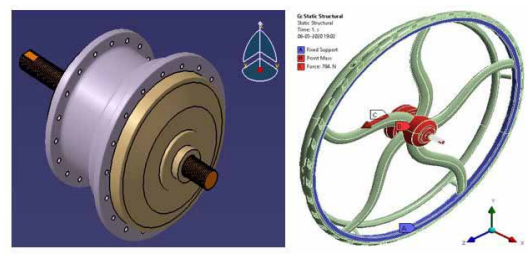

availability. Throughout the analysis, the structural steel is selected as a material for axle. The different materials along with physical and mechanical properties used for analysis purposes is shown in Table 1.

\subsection{Boundary Conditions and Meshing}

The standard earth-gravity is applied on the axle down to the Z-axis. It has to be considered as a no-load condition. The outer surfaces of the wheel are selected to apply for fixed support. The outer surfaces of the entire motor are selected to apply the motor weight. All surfaces of the axle are selected to apply the varying load. All the boundary conditions are shown in figure - 1. Meshing is an integral part of the engineering simulation process of ANSYS workbench. In this, complex geometries are divided into simple elements to use as discrete local approximations of the larger domain. It influences the convergence, accuracy, and speed of the simulation. Assign global mesh settings, Local mesh setting insertion, generate mesh and, mesh quality check are the four steps involved in ANSYS meshing. The meshing can over either part or body or whole geometry. The entire geometry meshing has called assembly meshing. In ANSYS, two algorithms like cutcell and tetrahedrons are available to perform the assembly meshing.

During meshing, FEA converts the whole geometry into nodes and elements. A node is a coordinate location in space where the physical property and Degrees of Freedom (DOFs) are defined. An element is a mathematical entity that indicates how the physical property and shape of an internal point are interpolated from the physical properties and node positions. The governing mathematical equations like partial and ordinary differential equations (PDE and ODE) are solved at the elements and nodes. It predicts the changes within the element and the results are plotted using line plots and colors. The elements are classified as Line elements, 2D Elements, Shell (3D) Elements, Solid or Brick elements. A line element has connected with two nodes called an edge. 2D elements are connected with either three or four edges comprising an area. 3D elements either triangular or quadrilateral with a specified thickness. Solid elements are enclosed 3D volumes with either four or more corner nodes. Meshing elements must be continuous or conformal, i.e, they all have to share common element edges and corner nodes. No elements should penetrate or overlap with any

Figure 2. The design Geometry of the proposed wheel.

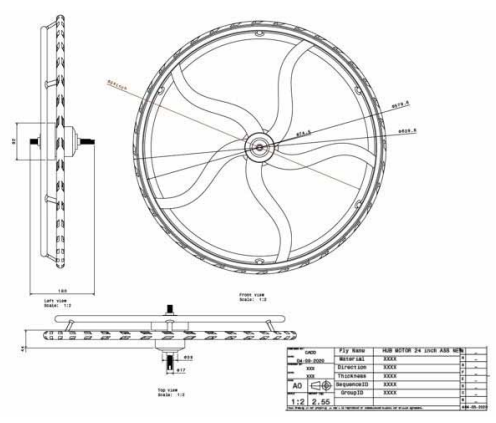


Table 1. Physical and mechanical properties of different material

\begin{tabular}{|c|c|c|c|c|c|c|c|}
\hline \multirow{2}{*}{ Property Name } & \multicolumn{7}{|c|}{ Type of material } \\
\cline { 2 - 8 } & $\begin{array}{c}\text { Aluminum } \\
\text { Alloy } \\
\text { (T6-6061) }\end{array}$ & $\begin{array}{c}\text { Aluminum } \\
\text { Alloy } \\
\text { (T6-7075) }\end{array}$ & $\begin{array}{c}\text { Aluminum } \\
\text { Alloy } \\
(\mathbf{7 0 0 3})\end{array}$ & $\begin{array}{c}\text { Aluminum } \\
\text { Alloy } \\
(\mathbf{6 0 8 2})\end{array}$ & $\begin{array}{c}\text { Mg-Alloy } \\
\text { AZ31BH24 }\end{array}$ & $\begin{array}{c}\text { Mg-Alloy } \\
\text { AZ91ET6 }\end{array}$ & $\begin{array}{c}\text { Mg-Alloy } \\
\text { MgAl3Znl }\end{array}$ \\
\hline Density (g/cm $\left.{ }^{3}\right)$ & 2.7 & 2.83 & 2.80 & 2.70 & 1.77 & 1.81 & 1.78 \\
\hline $\begin{array}{c}\text { Tensile strength } \\
\text { Ultimate (MPa) }\end{array}$ & 310 & 570 & 390 & 290 & 290 & 275 & 290 \\
\hline $\begin{array}{c}\text { Tensile strength } \\
\text { Yield (MPa) }\end{array}$ & 276 & 500 & 310 & 250 & 220 & 145 & 160 \\
\hline Poisson's Ratio & 0.33 & 0.33 & 0.32 & 0.33 & 0.35 & 0.35 & 0.35 \\
\hline $\begin{array}{c}\text { Young's modulus } \\
\text { (MPa) }\end{array}$ & 68900 & 71700 & 70000 & 71000 & 45000 & 44800 & 44000 \\
\hline $\begin{array}{c}\text { Shear Modulus } \\
\text { (MPa) }\end{array}$ & 26000 & 26000 & 26000 & 26000 & 17000 & 17000 & 17000 \\
\hline
\end{tabular}

other. All elements should be well-shaped, which involves restrictions on the edge angles. Because irregular structural boundaries make it difficult to get a good aspect ratio. The accuracy of the FEA has directly proportional to mesh quality as well as the computational resources involved. In general, Most FEA algorithms have automatic mesh generation capabilities. In such a case, triangular or a mix of triangular and quadrilateral mesh is common for surface structures. For solid structures, only tetrahedral elements are preferred. In general, Automatic mesh generation technology can generate an unstructured and structured meshing.

The structured mesh is typically all quad or hexahedral mesh having an equal number of adjacent elements that can be recognized by all interior nodes. The unstructured mesh generation is typically triangular and tetrahedral mesh. It relaxes the node valence requirement and allows any number of elements to meet at a single node (Chang, 2015). Most FEA codes currently in use for support of triangular or tetrahedral meshing can fit into one of three main approaches like octree, Delaunay, and advancing front. The mesh generation algorithm is able to define a mesh that is optimal without some form of post-processing to improve the overall quality of the elements. Smoothing and clean-up are the two main categories of mesh improvement.

The smoothing procedure involves an iterative process that repositions individual nodes to improve the quality of the element like aspect ratio and edge angles. Clean-up is a process that changes element connectivity. In the proposed design the mesh size for whole geometry has selected as $2 \mathrm{~mm}$ through the trial and error method.

\section{RESULTS}

An attempt has been taken to verify the load-bearing capacity of the proposed wheel for various weights of the hub motor. Four different Aluminum and three different magnesium material have used to make the Direct-drive wheel. The wheel tires have been omitted from the modeling process since it makes direct contact with the ground. The total Von-Mises stresses and deformation developed in various materials of each direct drive motorized alloy wheel with diameter 508, 610, and $660 \mathrm{~mm}$ is calculated under no-load condition are shown in Table-2. The Von-Mises stresses and deformation developed in aluminum and magnesium materials of various size wheels with different motor weights considering the load applied to each major part as 784, 686, $588 \mathrm{~N}$ is shown in Tables 3 and 4 respectively. Since all materials have high safety factor the modal and harmonic analysis has been done for only aluminum material. The first ten natural frequency modes of the 508, 610 and $660 \mathrm{~mm}$ 
Table 2. The deformation and von Mises stress developed in the selected materials under no load condition for different wheel size

\begin{tabular}{|c|c|c|c|c|c|c|c|}
\hline \multirow{3}{*}{$\begin{array}{c}\text { Type } \\
\text { of material }\end{array}$} & \multirow{3}{*}{$\begin{array}{l}\text { Motor Weight } \\
\text { (N) }\end{array}$} & \multicolumn{6}{|c|}{ Wheel size in millimeter $(\mathrm{mm})$} \\
\hline & & \multicolumn{2}{|c|}{$508(\mathrm{~mm})$} & \multicolumn{2}{|c|}{$610(\mathrm{~mm})$} & \multicolumn{2}{|c|}{$660(\mathrm{~mm})$} \\
\hline & & $\begin{array}{l}\text { Deformation } \\
\quad(\mathbf{m m})\end{array}$ & $\begin{array}{c}\text { von Mises } \\
\text { Stresses } \\
\text { (MPa) }\end{array}$ & $\begin{array}{l}\text { Deformation } \\
\quad(\mathrm{mm})\end{array}$ & $\begin{array}{c}\text { von Mises } \\
\text { Stresses } \\
\text { (MPa) }\end{array}$ & $\begin{array}{l}\text { Deformation } \\
\quad(\mathbf{m m})\end{array}$ & $\begin{array}{c}\text { von Mises } \\
\text { Stresses } \\
\text { (MPa) }\end{array}$ \\
\hline \multirow{4}{*}{$\begin{array}{l}\text { Aluminum } \\
\text { Alloy } \\
\text { (T6-6061) }\end{array}$} & 29.41 & 0.0030 & $1.029 \mathrm{e}^{-5}$ & 0.0024 & $2.324 \mathrm{e}^{-5}$ & 0.0025 & $2.146 \mathrm{e}^{-5}$ \\
\hline & 49.03 & 0.0047 & $1.713 \mathrm{e}^{-5}$ & 0.0072 & $2.689 \mathrm{e}^{-5}$ & 0.0045 & $3.118 \mathrm{e}^{-5}$ \\
\hline & 68.64 & 0.0065 & $2.354 \mathrm{e}^{-5}$ & 0.0101 & $3.715 \mathrm{e}^{-5}$ & 0.0061 & $4.089 \mathrm{e}^{-5}$ \\
\hline & 98.06 & 0.0091 & $3.317 \mathrm{e}^{-5}$ & 0.0143 & $5.254 \mathrm{e}^{-5}$ & 0.0086 & $5.545 \mathrm{e}^{-5}$ \\
\hline \multirow{4}{*}{$\begin{array}{l}\text { Aluminum } \\
\text { Alloy } \\
(6082)\end{array}$} & 29.41 & 0.0028 & $1.057 \mathrm{e}^{-5}$ & 0.0028 & $1.057 \mathrm{e}^{-5}$ & 0.0027 & $2.083 \mathrm{e}^{-5}$ \\
\hline & 49.03 & 0.0045 & $1.662 \mathrm{e}^{-5}$ & 0.0038 & $2.474 \mathrm{e}^{-5}$ & 0.0043 & $3.025 \mathrm{e}^{-5}$ \\
\hline & 68.64 & 0.0063 & $2.285 \mathrm{e}^{-5}$ & 0.0052 & $3.255 \mathrm{e}^{-5}$ & 0.0060 & $3.968 \mathrm{e}^{-5}$ \\
\hline & 98.06 & 0.0089 & $3.218 \mathrm{e}^{-5}$ & 0.0073 & $4.427 \mathrm{e}^{-5}$ & 0.0084 & $5.381 \mathrm{e}^{-5}$ \\
\hline \multirow{4}{*}{$\begin{array}{l}\text { Aluminum } \\
\text { Alloy } \\
\text { (T6-7075) }\end{array}$} & 29.41 & 0.0028 & $1.051 \mathrm{e}^{-5}$ & 0.0024 & $1.698 \mathrm{e}^{-5}$ & 0.0027 & $2.092 \mathrm{e}^{-5}$ \\
\hline & 49.03 & 0.0045 & $1.650 \mathrm{e}^{-5}$ & 0.0038 & $2.472 \mathrm{e}^{-5}$ & 0.0043 & $3.025 \mathrm{e}^{-5}$ \\
\hline & 68.64 & 0.0062 & $2.266 \mathrm{e}^{-5}$ & 0.0052 & $3.246 \mathrm{e}^{-5}$ & 0.0058 & $3.958 \mathrm{e}^{-5}$ \\
\hline & 98.06 & 0.0088 & $3.191 \mathrm{e}^{-5}$ & 0.0073 & $4.406 \mathrm{e}^{-5}$ & 0.0083 & $5.358 \mathrm{e}^{-5}$ \\
\hline \multirow{4}{*}{$\begin{array}{c}\text { Aluminum } \\
\text { Alloy } \\
\text { (7003) }\end{array}$} & 29.41 & 0.0028 & $1.059 \mathrm{e}^{-5}$ & 0.0024 & $1.712 \mathrm{e}^{-5}$ & 0.0027 & $2.109 \mathrm{e}^{-5}$ \\
\hline & 49.03 & 0.0046 & $1.693 \mathrm{e}^{-5}$ & 0.0034 & $2.494 \mathrm{e}^{-5}$ & 0.0044 & $3.052 \mathrm{e}^{-5}$ \\
\hline & 68.64 & 0.0063 & $2.328 \mathrm{e}^{-5}$ & 0.0052 & $3.276 \mathrm{e}^{-5}$ & 0.0060 & $3.996 \mathrm{e}^{-5}$ \\
\hline & 98.06 & 0.0090 & $3.280 \mathrm{e}^{-5}$ & 0.0074 & $4.450 \mathrm{e}^{-5}$ & 0.0084 & $5.412 \mathrm{e}^{-5}$ \\
\hline \multirow{4}{*}{$\begin{array}{c}\text { Mg-Alloy } \\
\text { AZ31BH24 }\end{array}$} & 29.41 & 0.0043 & $1.627 \mathrm{e}^{-5}$ & 0.0036 & $2.409 \mathrm{e}^{-5}$ & 0.0041 & $2.945 \mathrm{e}^{-5}$ \\
\hline & 49.03 & 0.0071 & $2.629 \mathrm{e}^{-5}$ & 0.0058 & $3.639 \mathrm{e}^{-5}$ & 0.0067 & $4.421 \mathrm{e}^{-5}$ \\
\hline & 68.64 & 0.0098 & $3.632 \mathrm{e}^{-5}$ & 0.0081 & $4.869 \mathrm{e}^{-5}$ & 0.0092 & $5.909 \mathrm{e}^{-5}$ \\
\hline & 98.06 & 0.0140 & $5.136 \mathrm{e}^{-5}$ & 0.0114 & $6.714 \mathrm{e}^{-5}$ & 0.0130 & $8.132 \mathrm{e}^{-5}$ \\
\hline \multirow{4}{*}{$\begin{array}{l}\text { Mg-Alloy } \\
\text { AZ91ET6 }\end{array}$} & 29.41 & 0.0044 & $1.636 \mathrm{e}^{-5}$ & 0.0036 & $2.431 \mathrm{e}^{-5}$ & 0.0042 & $2.973 \mathrm{e}^{-5}$ \\
\hline & 49.03 & 0.0071 & $2.643 \mathrm{e}^{-5}$ & 0.0059 & $3.666 \mathrm{e}^{-5}$ & 0.0067 & $4.461 \mathrm{e}^{-5}$ \\
\hline & 68.64 & 0.0099 & $3.650 \mathrm{e}^{-5}$ & 0.0081 & $4.901 \mathrm{e}^{-5}$ & 0.0069 & $5.950 \mathrm{e}^{-5}$ \\
\hline & 98.06 & 0.0140 & $5.161 \mathrm{e}^{-5}$ & 0.0115 & $6.755 \mathrm{e}^{-5}$ & 0.0131 & $8.183 \mathrm{e}^{-5}$ \\
\hline \multirow{4}{*}{$\begin{array}{l}\text { Mg-Alloy } \\
\text { MgAl3Znl }\end{array}$} & 29.41 & 0.0044 & $1.664 \mathrm{e}^{-5}$ & 0.0037 & $2.465 \mathrm{e}^{-5}$ & 0.0042 & $3.016 \mathrm{e}^{-5}$ \\
\hline & 49.03 & 0.0072 & $2.689 \mathrm{e}^{-5}$ & 0.0060 & $3.723 \mathrm{e}^{-5}$ & 0.0068 & $4.532 \mathrm{e}^{-5}$ \\
\hline & 68.64 & 0.0101 & $3.715 \mathrm{e}^{-5}$ & 0.0083 & $4.980 \mathrm{e}^{-5}$ & 0.0094 & $6.047 \mathrm{e}^{-5}$ \\
\hline & 98.06 & 0.0143 & $5.254 \mathrm{e}^{-5}$ & 0.0117 & $6.866 \mathrm{e}^{-5}$ & 0.0133 & $8.321 \mathrm{e}^{-5}$ \\
\hline
\end{tabular}

diameter wheel made with aluminum alloy (T6-6061) are shown in table -5. The deformation and von misses stress developed in a $508 \mathrm{~mm}$ wheel made with Aluminum alloy (T6-6061) concerning the natural frequencies is shown in the figure. 3. The maximum displacement point has confirmed through structural analysis. The safety factor for the proposed model can calculated from the results. 


\begin{tabular}{|c|c|c|c|c|c|c|c|c|}
\hline \multirow{3}{*}{ Type of material } & \multirow{3}{*}{$\begin{array}{l}\text { Motor } \\
\text { Weight } \\
\text { (N) }\end{array}$} & \multirow{3}{*}{$\begin{array}{c}\text { Load } \\
\text { (N) }\end{array}$} & \multicolumn{6}{|c|}{ Wheel size in millimeter $(\mathrm{mm})$} \\
\hline & & & \multicolumn{2}{|c|}{$508(\mathrm{~mm})$} & \multicolumn{2}{|c|}{$610(\mathrm{~mm})$} & \multicolumn{2}{|c|}{$660(\mathrm{~mm})$} \\
\hline & & & $\begin{array}{l}\text { Deformation } \\
\quad(\mathbf{m m})\end{array}$ & $\begin{array}{c}\text { von Mises } \\
\text { Stresses } \\
\text { (MPa) }\end{array}$ & $\begin{array}{l}\text { Deformation } \\
\quad(\mathrm{mm})\end{array}$ & $\begin{array}{l}\text { von Mises } \\
\text { Stresses } \\
\text { (MPa) }\end{array}$ & $\begin{array}{l}\text { Deformation } \\
\quad(\mathbf{m m})\end{array}$ & $\begin{array}{c}\text { von Mises } \\
\text { Stresses } \\
\text { (MPa) }\end{array}$ \\
\hline \multirow{9}{*}{$\begin{array}{l}\text { Aluminum } \\
\text { Alloy } \\
\text { (T6-6061) }\end{array}$} & \multirow{3}{*}{29.41} & 784 & 0.0450 & 0.0021 & 0.0778 & 0.0013 & 0.0500 & 0.0015 \\
\hline & & 686 & 0.0382 & 0.0018 & 0.0679 & 0.0011 & 0.0436 & 0.0013 \\
\hline & & 588 & 0.0328 & 0.0015 & 0.0581 & 0.0010 & 0.0372 & 0.0011 \\
\hline & \multirow{3}{*}{49.03} & 784 & 0.0440 & 0.0021 & 0.0770 & 0.0013 & 0.0492 & 0.0015 \\
\hline & & 686 & 0.0386 & 0.0018 & 0.0671 & 0.0011 & 0.0428 & 0.0013 \\
\hline & & 588 & 0.0333 & 0.0015 & 0.0573 & 0.0010 & 0.0364 & 0.0011 \\
\hline & \multirow{3}{*}{68.64} & 784 & 0.0444 & 0.0021 & 0.0762 & 0.0013 & 0.0484 & 0.0015 \\
\hline & & 686 & 0.0391 & 0.0018 & 0.0663 & 0.0011 & 0.0420 & 0.0013 \\
\hline & & 588 & 0.0338 & 0.0015 & 0.0565 & 0.0010 & 0.0356 & 0.0011 \\
\hline \multirow{9}{*}{$\begin{array}{l}\text { Aluminum } \\
\text { Alloy } \\
(6082)\end{array}$} & \multirow{3}{*}{29.41} & 784 & 0.0427 & 0.0021 & 0.0481 & 0.0014 & 0.0489 & 0.0015 \\
\hline & & 686 & 0.0374 & 0.0018 & 0.0433 & 0.0013 & 0.0426 & 0.0013 \\
\hline & & 588 & 0.0322 & 0.0015 & 0.0369 & 0.0011 & 0.0346 & 0.0011 \\
\hline & \multirow{3}{*}{49.03} & 784 & 0.0431 & 0.0021 & 0.0496 & 0.0014 & 0.0481 & 0.0015 \\
\hline & & 686 & 0.0379 & 0.0018 & 0.0433 & 0.0013 & 0.0418 & 0.0013 \\
\hline & & 588 & 0.0326 & 0.0015 & 0.0369 & 0.0011 & 0.0356 & 0.0011 \\
\hline & \multirow{6}{*}{29.41} & 784 & 0.0435 & 0.0021 & 0.0481 & 0.0014 & 0.0473 & 0.0015 \\
\hline & & 686 & 0.0383 & 0.0018 & 0.0417 & 0.0013 & 0.0411 & 0.0013 \\
\hline & & 588 & 0.0331 & 0.0015 & 0.0354 & 0.0011 & 0.0348 & 0.0011 \\
\hline \multirow{9}{*}{$\begin{array}{l}\text { Aluminum } \\
\text { Alloy } \\
\text { (T6-7075) }\end{array}$} & & 784 & 0.0424 & 0.0021 & 0.0493 & 0.0014 & 0.0485 & 0.0015 \\
\hline & & 686 & 0.0372 & 0.0018 & 0.0430 & 0.0013 & 0.0423 & 0.0013 \\
\hline & & 588 & 0.0320 & 0.0015 & 0.0367 & 0.0011 & 0.0361 & 0.0011 \\
\hline & \multirow{6}{*}{68.64} & 784 & 0.0428 & 0.0021 & 0.0485 & 0.0014 & 0.0477 & 0.0015 \\
\hline & & 686 & 0.0376 & 0.0018 & 0.0422 & 0.0013 & 0.0415 & 0.0013 \\
\hline & & 588 & 0.0324 & 0.0015 & 0.0359 & 0.0011 & 0.0353 & 0.0011 \\
\hline & & 784 & 0.0433 & 0.0021 & 0.0477 & 0.0014 & 0.0469 & 0.0015 \\
\hline & & 686 & 0.0381 & 0.0018 & 0.0414 & 0.0013 & 0.0408 & 0.0013 \\
\hline & & 588 & 0.0320 & 0.0015 & 0.0351 & 0.0011 & 0.0346 & 0.0011 \\
\hline \multirow{9}{*}{$\begin{array}{c}\text { Aluminum } \\
\text { Alloy } \\
(7003)\end{array}$} & \multirow{3}{*}{29.41} & 784 & 0.0426 & 0.0021 & 0.0496 & 0.0014 & 0.0489 & 0.0015 \\
\hline & & 686 & 0.0374 & 0.0018 & 0.0433 & 0.0013 & 0.0426 & 0.0013 \\
\hline & & 588 & 0.0322 & 0.0015 & 0.0369 & 0.0011 & 0.0364 & 0.0011 \\
\hline & & 784 & 0.0431 & 0.0021 & 0.0707 & 0.0013 & 0.0481 & 0.0015 \\
\hline & 49.03 & 686 & 0.0378 & 0.0018 & 0.0617 & 0.0012 & 0.0418 & 0.0013 \\
\hline & & 588 & 0.0326 & 0.0015 & 0.0526 & 0.0010 & 0.0356 & 0.0011 \\
\hline & & 784 & 0.0435 & 0.0021 & 0.0700 & 0.0013 & 0.0473 & 0.0015 \\
\hline & 68.64 & 686 & 0.0383 & 0.0018 & 0.0609 & 0.0012 & 0.0411 & 0.0013 \\
\hline & & 588 & 0.0331 & 0.0015 & 0.0518 & 0.0010 & 0.0348 & 0.0011 \\
\hline
\end{tabular}


Table 4. The deformation and von Mises stress developed in the selected Magnesium materials under various load condition for different wheel size

\begin{tabular}{|c|c|c|c|c|c|c|c|c|}
\hline \multirow{3}{*}{ Type of material } & \multirow{3}{*}{$\begin{array}{c}\text { Motor } \\
\text { Weight } \\
\text { (N) }\end{array}$} & \multirow{3}{*}{$\begin{array}{c}\text { Load } \\
(\mathbf{N})\end{array}$} & \multicolumn{6}{|c|}{ Wheel size in millimeter $(\mathbf{m m})$} \\
\hline & & & \multicolumn{2}{|c|}{$508(\mathrm{~mm})$} & \multicolumn{2}{|c|}{$610(\mathrm{~mm})$} & \multicolumn{2}{|c|}{$660(\mathrm{~mm})$} \\
\hline & & & $\begin{array}{l}\text { Deformation } \\
\text { (mm) }\end{array}$ & $\begin{array}{c}\text { von Mises } \\
\text { Stresses } \\
\text { (MPa) }\end{array}$ & $\begin{array}{l}\text { Deformation } \\
\text { (mm) }\end{array}$ & $\begin{array}{c}\text { von Mises } \\
\text { Stresses } \\
\text { (MPa) }\end{array}$ & $\begin{array}{l}\text { Deformation } \\
\text { (mm) }\end{array}$ & $\begin{array}{l}\text { von Mises } \\
\text { Stresses } \\
\text { (MPa) }\end{array}$ \\
\hline \multirow{9}{*}{$\begin{array}{c}\text { Mg-Alloy } \\
\text { AZ31BH24 }\end{array}$} & \multirow{3}{*}{29.41} & 784 & 0.1292 & 0.0016 & 0.1037 & 0.0015 & 0.0771 & 0.0016 \\
\hline & & 686 & 0.1131 & 0.0014 & 0.0905 & 0.0013 & 0.0672 & 0.0014 \\
\hline & & 588 & 0.0967 & 0.0012 & 0.0773 & 0.0011 & 0.0574 & 0.0012 \\
\hline & \multirow{3}{*}{49.03} & 784 & 0.1281 & 0.0016 & 0.1024 & 0.0015 & 0.0758 & 0.0016 \\
\hline & & 686 & 0.1117 & 0.0014 & 0.0893 & 0.0013 & 0.0660 & 0.0014 \\
\hline & & 588 & 0.0952 & 0.0012 & 0.0761 & 0.0011 & 0.0561 & 0.0012 \\
\hline & \multirow{3}{*}{68.64} & 784 & 0.1267 & 0.0016 & 0.1034 & 0.0015 & 0.0746 & 0.0016 \\
\hline & & 686 & 0.1102 & 0.0014 & 0.0893 & 0.0013 & 0.0647 & 0.0014 \\
\hline & & 588 & 0.0938 & 0.0012 & 0.0761 & 0.0011 & 0.0549 & 0.0012 \\
\hline \multirow{9}{*}{$\begin{array}{l}\text { Mg-Alloy } \\
\text { AZ91ET6 }\end{array}$} & \multirow{3}{*}{29.41} & 784 & 0.1301 & 0.0016 & 0.1041 & 0.0015 & 0.0774 & 0.0016 \\
\hline & & 686 & 0.1136 & 0.0014 & 0.0908 & 0.0013 & 0.0675 & 0.0014 \\
\hline & & 588 & 0.0970 & 0.0012 & 0.0776 & 0.0011 & 0.0579 & 0.0012 \\
\hline & \multirow{3}{*}{49.03} & 784 & 0.1286 & 0.0016 & 0.1028 & 0.0015 & 0.0761 & 0.0016 \\
\hline & & 686 & 0.1121 & 0.0014 & 0.0896 & 0.0013 & 0.0662 & 0.0014 \\
\hline & & 588 & 0.0956 & 0.0012 & 0.0764 & 0.0011 & 0.0563 & 0.0012 \\
\hline & \multirow{3}{*}{68.64} & 784 & 0.1272 & 0.0016 & 0.0651 & 0.0017 & 0.0748 & 0.0016 \\
\hline & & 686 & 0.1106 & 0.0014 & 0.0564 & 0.0015 & 0.0650 & 0.0014 \\
\hline & & 588 & 0.0941 & 0.0012 & 0.0478 & 0.0013 & 0.0551 & 0.0012 \\
\hline \multirow{9}{*}{$\begin{array}{l}\text { Mg-Alloy } \\
\text { MgAl3Znl }\end{array}$} & \multirow{3}{*}{29.41} & 784 & 0.1321 & 0.0017 & 0.0661 & 0.0017 & 0.0785 & 0.0016 \\
\hline & & 686 & 0.1153 & 0.0014 & 0.0573 & 0.0015 & 0.0684 & 0.0014 \\
\hline & & 588 & 0.0985 & 0.0012 & 0.0485 & 0.0013 & 0.0584 & 0.0012 \\
\hline & \multirow{3}{*}{49.03} & 784 & 0.1306 & 0.0017 & 0.0674 & 0.0017 & 0.0702 & 0.0016 \\
\hline & & 686 & 0.1139 & 0.0014 & 0.0586 & 0.0015 & 0.0671 & 0.0014 \\
\hline & & 588 & 0.0971 & 0.0012 & 0.0498 & 0.0013 & 0.0571 & 0.0012 \\
\hline & \multirow{3}{*}{68.64} & 784 & 0.1292 & 0.0017 & 0.0661 & 0.0017 & 0.0759 & 0.0016 \\
\hline & & 686 & 0.1124 & 0.0014 & 0.0573 & 0.0015 & 0.0659 & 0.0014 \\
\hline & & 588 & 0.0956 & 0.0012 & 0.0485 & 0.0013 & 0.0558 & 0.0012 \\
\hline
\end{tabular}

\section{CONCLUSION}

This experiment applied a direct drive wheel design to a manual wheelchair to improve its mobility. A direct-drive motor has embedded to the rear wheel of the manual wheelchair. According to the values shown in Table-2, No material experienced the von Misses stresses beyond their ultimate tensile strength. The deformation is further decreased as wheel diameter is increased. The von Misses stress and deformation values are increased as motor weight increased irrespective of the material. The values of tables -3 and 4 indicate the results for various load conditions. The values in the Table- 3 
Table 5. The first ten natural frequency modes of the 508,610 and $660 \mathrm{~mm}$ diameter wheel made with aluminum alloy (T6-6061)

\begin{tabular}{|c|c|c|c|}
\hline \multirow{2}{*}{ S.No } & \multicolumn{2}{|c|}{ Different frequency modes (Hz) } \\
\cline { 2 - 4 } & $\mathbf{5 0 8}(\mathbf{m m})$ & $\mathbf{6 1 0}(\mathbf{m m})$ & $\mathbf{6 6 0}(\mathbf{m m})$ \\
\hline 1. & 181.7 & 123.38 & 104.8 \\
\hline 2. & 518.56 & 367.5 & 319.28 \\
\hline 3. & 518.77 & 367.6 & 319.37 \\
\hline 4. & 717.56 & 502.53 & 430.38 \\
\hline 5. & 884.67 & 620.3 & 528.92 \\
\hline 6. & 884.76 & 620.37 & 528.95 \\
\hline 7. & 1014.3 & 642.05 & 539.1 \\
\hline 8. & 1104.3 & 642.74 & 539.59 \\
\hline 9. & 1104.8 & 795.62 & 672.04 \\
\hline 10. & 1188.7 & 800.98 & 724.96 \\
\hline
\end{tabular}

shows that von Misses stress and deformation values are increased concerning the diameter of the wheel. These values are decreased as the load and weight of the motor is decreased and these values are not beyond the tensile strength of the four aluminum materials. Form Table- 4 it can be observed that the three magnesium alloy material experienced low von Misses stresses and deformation values compared with four aluminum materials. Independent of the material and load condition, the maximum stress experienced has recorded as less than $1 \mathrm{Mpa}$. It produces a high safety factor for the no-load condition and all materials experience a negligible deformation corresponding to the stress. Form no-load and load condition analysis it can conclude that the material selection for real-time implementation has to be taken based on the cost of the material and market availability. According to the table-5, the minimum and maximum natural frequency modes for $508 \mathrm{~mm}, 610 \mathrm{~mm}, 660 \mathrm{~mm}$ wheels are recorded as $181.7 \& 1188.7,123.38 \& 800.98$, and $104.8 \& 724.96 \mathrm{~Hz}$ respectively. From this, the authors conclude that the natural mode frequencies are decreasing concerning the wheel size. These results can help to validate the performance of the physical modal in real-time. From figure-3, it has been concluded that the $508 \mathrm{~mm}$ wheel experiences the maximum stress and phase deviations at the corresponding natural mode frequencies and indicates the accuracy of the result.

However, the direct drive wheel for manual wheelchair proposed in this paper has designed by deriving the optimal power options based on various wheelchair designs developed across the

Figure 3. The variations in amplitude and phase angle of von Mises stress and Deformation on a $508 \mathrm{~mm}$ diameter wheel for various natural frequencies

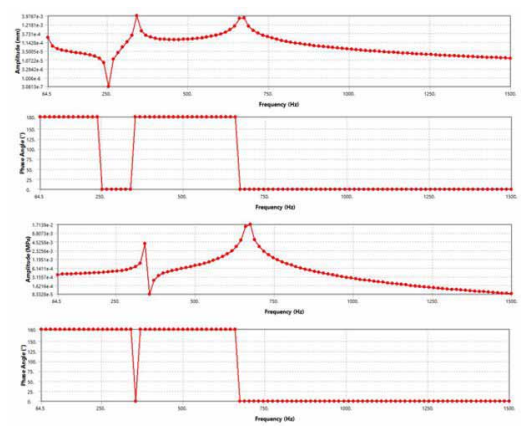


globe. It can suite for developing countries and doesn't reflect the difference between the physical condition of Westerners and Asians. The authors expect that the disabled and elder people using a manual wheelchair who previously depending on caregivers will be able to smoothly use a powered wheelchair. The proposed powered wheel manufacturing cost is very less compared to the existing powered wheelchairs. Also, the authors expect that by expanding their right to mobility they will be able to improve the quality of life.

\section{ACKNOWLEDGMENT}

This work is supported by Visvesvaraya Ph.D. Scheme of the Department of Electronics and Information Technology (DietY), Ministry of Communications and IT, Government of India [grant number Ph.D-MLA/4(95)/2015-16]. 


\section{REFERENCES}

Avutu, S. R., Bhatia, D., \& Reddy, B. V. (2016). Design of low-cost manual cum electric-powered wheelchair for disabled person's to use in indoor. Paper presented at the 2016 2nd International Conference on Next Generation Computing Technologies (NGCT).

Avutu, S. R., Bhatia, D., \& Reddy, B. V. (2017). Design of an appropriate manual cum powered wheelchair. Paper presented at the 2017 IEEE International Conference on Smart Technologies and Management for Computing, Communication, Controls, Energy and Materials (ICSTM).

Chang, K.-H. (2015). Structural Analysis. In K.-H. Chang (Ed.), e-Design (pp. 325-390). Academic Press. doi:10.1016/B978-0-12-382038-9.00007-7

Chong, W. S., Shin, M. Y., \& Yu, C. H. (2019). Structural analysis of carbon composite frame for foldable electric wheelchair development. Journal of Mechanics in Medicine and Biology, 19(07), 1940045. doi:10.1142/ S0219519419400451

Flemmer, C. L., \& Flemmer, R. C. (2016). A review of manual wheelchairs. Disability and Rehabilitation. Assistive Technology, 11(3), 177-187. doi:10.3109/17483107.2015.1099747 PMID:26549405

Hasan, M. Z., \& Rashid, M. (2019). Design and Finite Element Analysis of an Eight Wheel Stair Climbing Cart. Strojnícky časopis-. Jixie Gongcheng Xuebao, 69(4), 89-104.

Hussein, H. T., Ammar, M., \& Hassan, M. M. (2017). Three Phase Induction Motor's Stator Turns Fault Analysis Based on Artificial Intelligence. International Journal of System Dynamics Applications, 6(3), 1-19. doi:10.4018/IJSDA.2017070101

Jordan, R. W., Sloan, R., \& Saithna, A. (2018). Should we avoid shoulder surgery in wheelchair users? A systematic review of outcomes and complications. Orthopaedics \& Traumatology: Surgery \& Research, 104(6), 839-846. doi:10.1016/j.otsr.2018.03.011 PMID:29705081

Kharola, A., \& Patil, P. P. (2017). Position and Tilt Control of Two-Wheeled Robot (TWR): A Neuro-Fuzzy Approach. International Journal of System Dynamics Applications, 6(4), 17-33. doi:10.4018/IJSDA.2017100102

Kim, Y., Kim, J., Kim, H. S., \& Seo, T. (2019). Curved-spoke tri-wheel mechanism for fast stair-climbing. IEEE Access: Practical Innovations, Open Solutions, 7, 173766-173773. doi:10.1109/ACCESS.2019.2956163

Mistarihi, M. Z., Okour, R. A., \& Mumani, A. A. (2020). An integration of a QFD model with Fuzzy-ANP approach for determining the importance weights for engineering characteristics of the proposed wheelchair design. Applied Soft Computing, 90, 106136. doi:10.1016/j.asoc.2020.106136

Murray, R. C., Ophaswongse, C., \& Agrawal, S. K. (2019). Design of a wheelchair robot for active postural support. Journal of Mechanisms and Robotics, 11(2), 020911. doi:10.1115/1.4042544

Nikabadi, M. S., \& Hakaki, A. (2018). A dynamic model of effective factors on open innovation in manufacturing small and medium sized companies. International Journal of System Dynamics Applications, 7(1), 1-26. doi:10.4018/IJSDA.2018010101

Salima, M., Loubna, A., \& Riad, T. (2018). A global stability of linearizing control of induction motor for PV water pumping application. International Journal of System Dynamics Applications, 7(3), 31-56. doi:10.4018/ IJSDA.2018070102

Sang, L., Yamamura, M., Dong, F., Gan, Z., Fu, J., Wang, H., \& Tian, Y. (2020). Analysis, design, and experimental research of a novel wheelchair-stretcher assistive robot. Applied Sciences (Basel, Switzerland), 10(1), 264. doi:10.3390/app10010264

Sateesh Reddy, A., Sudip, P., \& Dinesh, B. (2019). Design and Feasibility Test of an Indigenous Motorized Wheel for Manual Wheelchair. International Journal of Manufacturing, Materials, and Mechanical Engineering, 9(3), 42-55. doi:10.4018/IJMMME.2019070104

Song, Z., Tian, C., \& Dai, J. S. (2019). Mechanism design and analysis of a proposed wheelchair-exoskeleton hybrid robot for assisting human movement. Mechanical Sciences, 10(1), 11-24. doi:10.5194/ms-10-11-2019 
Yasuda, G. I. (2020). Design and Implementation of Distributed Autonomous Coordinators for Cooperative MultiRobot Systems. In Robotic Systems: Concepts, Methodologies, Tools, and Applications (pp. 324-339). IGI Global.

Sateesh Reddy Avutu is currently Research Fellow (Visvesvaraya Ph.D Scheme) at School of technology, Biomedical Engineering Department, North Eastern Hill University, Shillong, India. It is a Central University located in the northeast part of the country. He received his M. Tech degree from Tezpur University (Central University), Tezpur, India. He published more than 15 International journal and conference papers.

Sudip Paul is currently an Assistant Professor in Department of Biomedical Engineering, School of Technology, North-Eastern Hill University (NEHU), Shillong, India. He completed his Post doctoral research at School of Computer Science and Software Engineering, The University of Western Australia, Perth. He was one of the most precious fellowship awardee (Biotechnology Overseas Associateship for the Scientists working in North Eastern States of India: 2017-18 supported by Department of Department of Biotechnology, Government of India). He received his Ph.D degree from Indian Institute of Technology (Banaras Hindu University), Varanasi with specialization in Electrophysiology and brain signal analysis. He has many credentials in his credit out of which his First Prize in Sushruta Innovation Award 2011 sponsored by Department of Science and Technology, Govt. of India and also he also organized many workshops and conferences out of which most significant are the 29th Annual meeting of the Society for Neurochemistry, India and IRBO/APRC Associate School 2017. Dr. Sudip published more than 90 International journal and conference papers and also filled four patents. Recently he completed three book projects and five are ongoing as editor. Dr. Sudip is a member of different Societies and professional bodies, including APSN, ISN, IBRO, SNCI, SfN and IEEE. He received many awards specially World federation of Neurology (WFN) travelling fellowship, Young Investigator Award, IBRO Travel Awardee and ISN Travel Awardee. Dr. Sudip also contributed his knowledge in different international journals as editorial board members. He has presented his research accomplishments in USA, Greece, France, South Africa and Australia. He is presently associated as Joint Secretary for the Biomedical Engineering Society of India. 